\title{
The validity and reliability of the patient enablement instrument (PEI) after GP appointments in Finnish health care centres
}

\author{
Elina Tolvanen ${ }^{1,2,3^{*}}$ D, Tuomas H. Koskela ${ }^{1}$, Mika Helminen ${ }^{3,4}$ and Elise Kosunen ${ }^{1,5}$
}

\begin{abstract}
Background: The aim of this study was to assess the validity and reliability of the Patient Enablement Instrument (PEI) in Finnish health care centre patients. A pilot study was conducted to assess the content validity of the PEI. A questionnaire study in three health care centres in Western Finland was performed in order to assess acceptability, construct validity, internal consistency, and measurement error of the instrument. A telephone interview 2 weeks after the appointment was performed to evaluate reproducibility.

Results: The pilot study with 17 participants indicated good content validity of the PEI. In the questionnaire study, altogether 483 with a completed PEI score were included in the analyses. Factor analysis and item-scale correlations suggested high structural validity. The internal consistency of the instrument was high (Cronbach's $a=0.93$ ). The PEI score diminished strongly over the two-week period.

Conclusions: The PEl has good content validity and acceptability, good construct validity, high internal consistency but low reproducibility. Thus, the PEI seems to be an applicable tool to measure patient enablement in Finnish primary health care.
\end{abstract}

Keywords: Patient enablement instrument, Validity, Reliability, Finland

\section{Background}

The patient's experience of care is one of the essential elements when assessing health care quality. To explore this, many health-related patient-reported outcome (HRPRO) measurements have been created, and new ones are constantly in development [1]. In Finland, the health care system is about to undergo a large reform, and one aspect of this will involve the client's wider freedom to choose where to obtain health and social services [2]. Under these circumstances, instruments to evaluate health care quality are needed. In addition, in order to

\footnotetext{
* Correspondence: elina.tolvanen@tuni.fi

${ }^{1}$ Faculty of Medicine and Health Technology, Tampere University, c/o coordinator Leena Kiuru, Arvo Building B, 33014 Tampere, Finland

${ }^{2}$ Pirkkala Municipal Health Centre, Pirkkala, Finland

Full list of author information is available at the end of the article
}

evaluate the appropriateness of the available instruments, we need to assess their validity and reliability.

The concepts of validity and reliability are complex and have several definitions and interpretations that are often used interchangeably. The international COSMIN committee has developed a consensus for defining the psychometric properties of HR-PRO measurements [3]. We have used the COSMIN checklist for methodological studies [4] as a guideline when designing the study, as well as the recently published COSMIN Risk for Bias checklist when writing this paper [5].

Figure 1 presents the different domains of validity and reliability that have been adapted from the COSMIN guidelines [4]. According to the COSMIN criteria, the quality of an HR-PRO measurement can be divided into three domains: validity, reliability, and responsiveness 

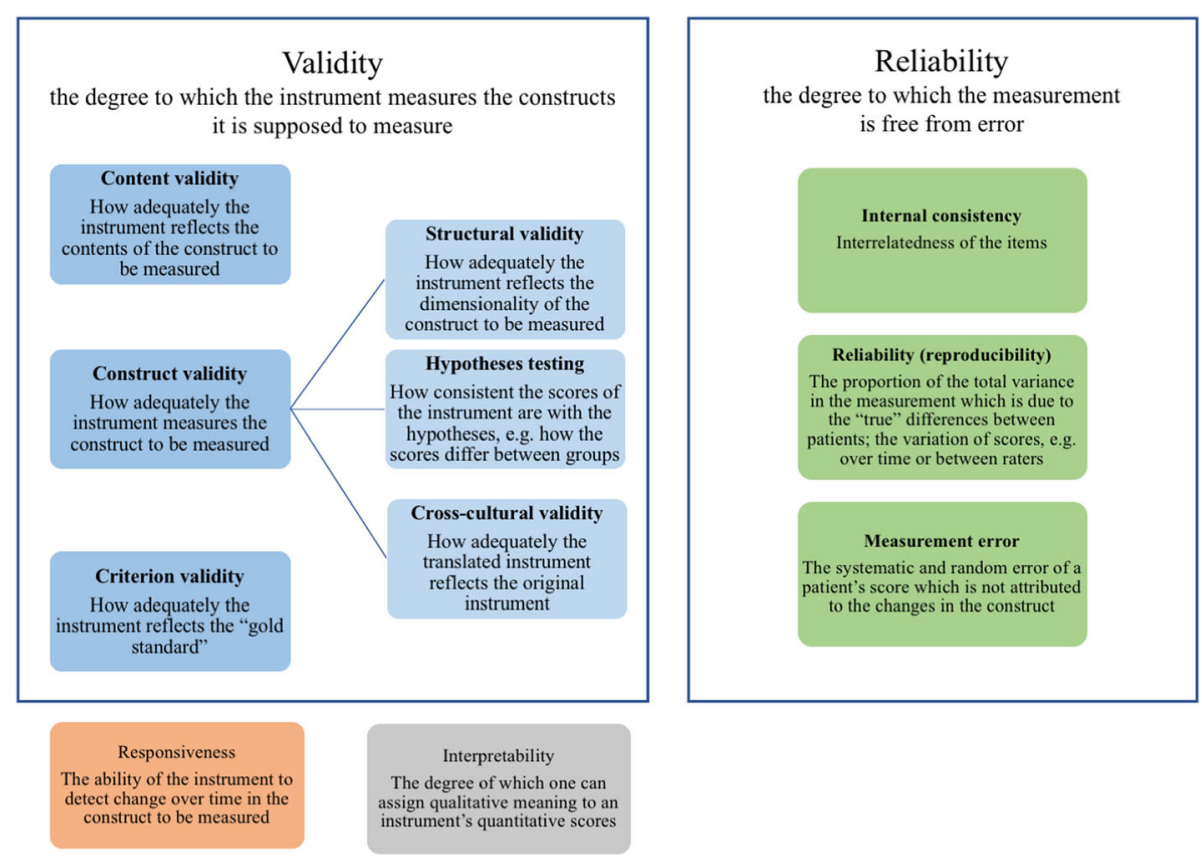

Fig. 1 The concept figure of validity and reliability, adapted from: L.B. Mokkink et al. The COSMIN checklist for assessing the methodological quality of studies on measurement properties of health status measurement instruments: An international Delphi study, Qual. Life Res. 19 (2010) 539-549

[3]. Validity is defined as the degree to which the instrument measures the constructs it is supposed to measure. Reliability refers to the degree to which the measurement is free from measurement error. Responsiveness is defined as the ability of the instrument to detect change over time in the construct to be measured [3]. Furthermore, two separate concepts exist: interpretability refers to the degree to which one can assign qualitative meaning to an instrument's quantitative scores [3], and acceptability addresses how acceptable the instrument is for the respondents to complete [1].

Patient enablement is defined as the patient's ability to understand and cope with illness and life after a consultation [6]. It is suggested to be a useful HR-PRO in primary health care [6-8]. The Patient Enablement instrument (PEI) is a six-item questionnaire addressed to the patient immediately after a consultation (Fig. 2). The items in the PEI questionnaire enquire the degree to which patients feel able to 1) understand their problem(s)/illness, 2) cope with the problem(s)/illness, 3) keep themselves healthy, 4) cope with life, 5) be confident about their health, and 6) help themselves after a consultation [6]. The PEI has been applied in several countries [6, 9-16].

Regarding factors associated with patient enablement, some studies have found that patient's older age is associated with higher enablement scores $[9,11,16]$. However, there are contradictory results $[10,13,14,17]$. Having one $[10,18]$ or several chronic diseases [19], or lower self-perceived health status $[11,17,19]$ have been associated with lower enablement in previous studies. PEI scores also seem to vary according to the patients' ethnic background [9, 10, 20, 21]. Furthermore, longer consultations, $[6,9,12,21-24]$, positive experiences of doctor-patient communication $[10,25,26]$ and the doctor's empathy $[19,27]$ have been associated with higher enablement, as has higher patient satisfaction [25, 28]. On the other hand, the PEI seems to measure different outcome compared to patient satisfaction instruments $[7,16,29,30]$.

All items included in the PEI are designed to measure the same underlying concept, namely patient enablement. In earlier studies, the internal consistency of the instrument has been reported to be high $[6,7,9,13,14,16,31$, 32]. Studies regarding the reproducibility (or reliability over time) of the PEI have produced contradictory results, with either a minimal change over time $[14,33]$ or lower scores in the retest compared to the baseline [13, 15, 34]. However, there are only a few studies on the PEI in the Nordic countries $[13,35]$, and none that evaluate the psychometric properties of the PEI in the Finnish context.

The PEI was developed in the UK, where GP consultation times are short $(5-8 \mathrm{~min})[6,9,20,27]$ and primary health care is maintained by independent GP practices. In Finland, the universal public health care system is organised by the municipalities, which provide services in multidisciplinary health care centres/stations. The appointments are usually fairly long, from 15 to 30 


\begin{tabular}{|c|c|c|c|c|c|}
\hline $\begin{array}{l}\text { As a result of your visit to the doctor } \\
\text { today, do you feel you are.. }\end{array}$ & $\begin{array}{l}\text { Much } \\
\text { better }\end{array}$ & Better & Same & Less & $\begin{array}{c}\text { Not } \\
\text { applicable }\end{array}$ \\
\hline able to understand your illness & $\square$ & $\square$ & $\square$ & $\square$ & $\square$ \\
\hline able to cope with your illness & $\square$ & $\square$ & $\square$ & $\square$ & $\square$ \\
\hline able to keep yourself healthy & $\square$ & $\square$ & $\square$ & $\square$ & $\square$ \\
\hline \multirow[t]{2}{*}{ able to cope with life } & $\square$ & $\square$ & $\square$ & $\square$ & $\square$ \\
\hline & $\begin{array}{l}\text { Much } \\
\text { more }\end{array}$ & More & Same & Less & $\begin{array}{c}\text { Not } \\
\text { applicable }\end{array}$ \\
\hline confident about your health & $\square$ & $\square$ & $\square$ & $\square$ & $\square$ \\
\hline able to help yourself & $\square$ & $\square$ & $\square$ & $\square$ & $\square$ \\
\hline
\end{tabular}

Scoring: Much better $=2$, Better $=1$, Same $=0$, Less $=-1$, Not applicable $=0$

Usually, the categories "Same" and Less" are combined and scored 0

Original PEI: Howie JG, Heaney DJ, Maxwell M. Measuring quality in general practice. Pilot study of a needs, process and outcome measure. Occas Pap R Coll Gen Pract. 1997;(75):i-xii, 1-32.

Fig. 2 Patient Enablement Instrument

min, and several issues are usually handled within the same appointment.

The aim of this study is to assess the validity and reliability of the PEI in Finnish health care centre patients, focusing on the acceptability, content and construct validity, internal consistency, and reliability of the instrument.

\section{Methods}

\section{Study design}

This study consisted of three parts: 1) a pilot study, 2) a questionnaire study with forms before (A) and immediately after (B) the appointment with a GP at a health care centre, and 3) telephone interviews 2 weeks after the appointment. The study design and the detailed information about the purpose of each part is presented in Fig. 3. In the pilot study, the goal was to recruit 10-20 participants. For an $80 \%$ chance of detecting a 0.5 -point difference in the PEI score between the two groups, 350 and 90 participants were needed for the questionnaire study and telephone interviews, respectively. Two weeks has been considered a suitable interval for test-retest measurements when evaluating patient-reported outcomes [36]. Furthermore, telephone surveys seem to produce similar results as face-to-face surveys [37].

Questionnaire A (before the appointment) included questions about the patient's self-management, expectations about the consultation, reason for the appointment, and waiting times. Questionnaire B (after the appointment) included the PEI, other assessments of the appointment, and the patient's demographic information. The telephone interview included information about health service use in the interim period, the PEI, and comparison questions about patient satisfaction, benefit, involvement, and instruction evaluation. Because the patients should be "stable" between the two measurements (meaning that there had been no new interventions) [4], patients who had visited a doctor in primary or secondary care within the two-week interim period were excluded from the test-retest analyses.

\section{Patient enablement instrument and item scoring}

In 2014, the PEI questionnaire had been formally backtranslated into Finnish as a part of a larger study [35]. Our research team, along with one professional translator (naive to both versions of the PEI), evaluated the translation and concluded that it was faithful.

The options in the PEI are "much better/more" (2 points), "better/more" (1 point), "same" (0 points), "less" (- 1 point), and "not applicable" (0 points), thus leading to a sum score ranging from -6 to 12 . Usually, the "same" and "less" options are combined [6, 12, 13], but we wanted to explore whether the negative option should be preserved in the questionnaire, as was done in one previous study [14]. The PEI score could be calculated when at least three of six questions had been answered [6]. Researchers are unanimous on which PEI scores reflect "adequate" or "good" enablement after consultation. For grouping purposes, researchers have used a cut-off point of one (PEI score 0 versus PEI score $\geq 1)$ [10] or six [6], or have compared PEI scores below and above the average on current study population [19].

The questions which were compared to the PEI indicated patient satisfaction, experienced benefit, patient involvement, and instruction evaluation. The comparison 


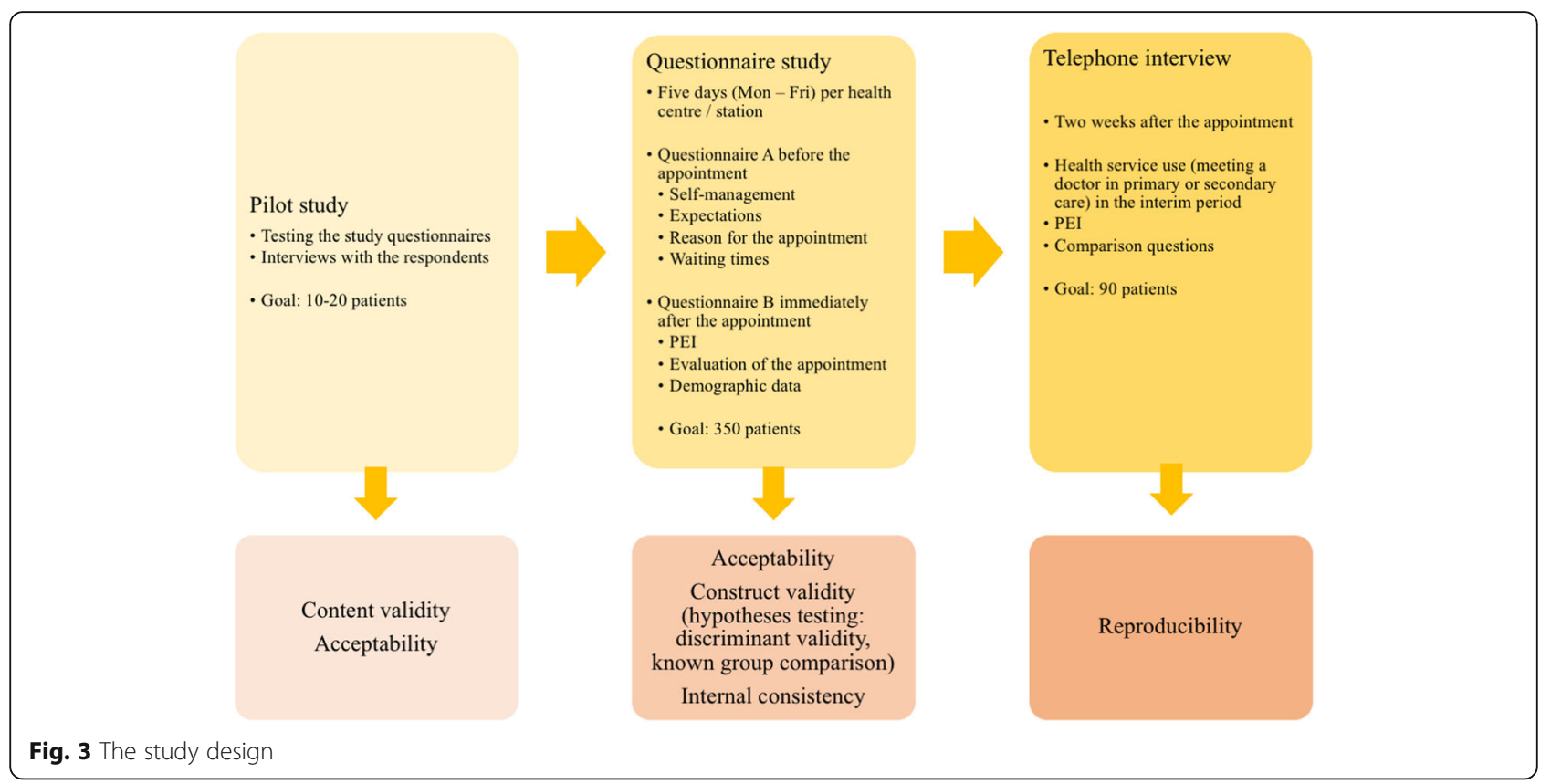

questions are presented in the Table 1. The comparison questions were measured on a 4-point Likert scale.

\section{Data collection}

The study data were collected between February and May 2017. The study was conducted in three municipalities in the Pirkanmaa district in Western Finland: Hämeenkyrö, Pirkkala, and Tampere. Hämeenkyrö is a rather rural county with a sizable elderly population. Pirkkala is a semi-rural county with a relatively youthful population situated next to the large city of Tampere. Tampere is the third largest city in Finland, with 230, 000 inhabitants and a sizable population of young adults.

The pilot study was conducted at Pirkkala health care centre in February 2017. During 1 day, the researcher (ET) approached patients in the waiting room of the health centre and asked them to participate. The participants were requested to fill out the study questionnaires and to have a brief interview afterwards with the researcher. The participants had to evaluate e.g. the appropriateness and relevance of the questions.

During the data collection period, the goal was to recruit all patients who had an appointment with a GP at the health centre during a five-day period (Monday to Friday, during office hours). The researcher (ET) or research assistants tried to approach everyone who came to the waiting room of the health centre/station during office hours. All the participants were informed about the study both orally and in writing, and they gave written consent. If the participant had difficulties with filling in the questionnaire (e.g. due to deteriorated vision), the research assistants helped them. The exclusion criteria were age under 18 years, insufficient Finnish skills, and severity of illness preventing participation in the study. In addition, patients who had an appointment with a GP in maternity care or student care were excluded.

\section{Assessing validity and reliability: data analysis}

All the statistical analyses were performed with IBM SPSS version 25 .

\section{Content validity and acceptability}

The content validity of the PEI in the Finnish context was evaluated during the pilot study. In the questionnaire study, all patients who had a valid PEI score after the appointment were included in the analysis.

Table 1 The comparison questions

I fully agree

I partly agree

I partly disagree

I fully disagree

$\mathrm{N} / \mathrm{A}^{\mathrm{a}}$

I would recommend this doctor to a friend or a relative

I benefited from my appointment with this doctor

I was involved in the decisions made at the appointment

I got adequate instructions to carry on with my care

${ }^{\mathrm{a}} \mathrm{N} / \mathrm{A}=$ not applicable 
Completion rates, distributions, and the means of the PEI items were analysed in order to assess the acceptability of the instrument.

\section{Construct validity}

The unidimensionality of the instrument, indicating reliability and structural validity, was evaluated by principal component factor analysis with Varimax rotation. Factor analysis should produce one factor with an eigenvalue > 1 , and each component should have similar factor loading. Furthermore, the structural validity was evaluated by item-scale correlations with the hypothesis that they should be higher than 0.7. Hypothesis testing was evaluated by comparing the PEI to questions measuring patient satisfaction, benefit, involvement, and instruction evaluation (indicating discriminant validity), plus known group comparison. The hypotheses were that the correlation between the PEI score and the comparison questions would be less than 0.4 ; and that the PEI scores would be lower among patients with a non-urgent reason for consultation, more chronic conditions, and a worse state of health; and the PEI is the same across gender and age groups. The Mann-Whitney $U$ test and the Kruskal-Wallis test were used to compare distributions across groups.

\section{Internal consistency}

Internal consistency between the questionnaire items was evaluated by counting the Cronbach alphas with confidence intervals. A value $>0.7$ is considered adequate [38].

\section{Reliability (reproducibility)}

Reliability over time was analysed by kappa statistics. The mean PEI and comparison question scores between the questionnaire study and telephone interview were compared by the Wilcoxon signed rank test.

\section{Measurement error}

The standard error of measurement (SEM) was calculated with the following formula: $S E M=S D \sqrt{1-r}$, where $S D$ is the standard deviation of the test score and $r$ is the reliability coefficient of the test, usually Cronbach's alpha, Cohen's Kappa, or some similar coefficient [39].

\section{Results}

\section{Content validity: the pilot study}

Altogether, 32 patients heading for a GP appointment were reached, 21 patients gave their consent, and 17 patients completed the pilot study. The mean age of the participants was 59.3 years (range 23-89) and 10 of them (58.8\%) were female. In general, the patients accepted the study questionnaires well. The questionnaires were filled thoroughly and the majority of the respondents found the questions important and relevant. After the pilot study, only minor corrections were made to the questionnaires; the PEI part was not changed.

\section{The questionnaire study}

The data collection in three health centres took a total of 17 days. The patient recruitment process and division for the analyses is presented in Fig. 4. During the data collection period, we reached 940 patients heading for a GP appointment, which was $79.3 \%$ of all the patients (information derived from the ICT system in the health care centres). Of those, 546 eligible patients gave their consent to participate. Altogether 118 patients were excluded during the recruitment process, and 63 patients were excluded due to uncompleted questionnaire B or the PEI part.

The demographic factors of the participants are presented in Table 2. Of the 546 participants, 483 patients had a completed PEI score (fewer than three options missing) and were thus included in the analyses. The mean age of the participants was 58.5 years (range 1897, SD 19.1) and 313 (64.8\%) were female. Furthermore, 175 participants were included in the test-retest analyses. When comparing groups by participation in the telephone interview, the groups differed significantly (data not shown). For instance, the telephone interviewees were older and had more chronic illnesses.

\section{Acceptability}

The overall response rate was $64.4 \%$ (267 refused +483 completed). The mean PEI score immediately after the appointment was 3.78 (range 0-12, SD 3.83). Altogether 131 of 483 (27.1\%) had the floor (0 points) score and 37 (7.7\%) the ceiling (12 points) score. There were only 16 respondents $(3.3 \%)$ with missing items. In addition, it was not possible to compute the PEI score in 63 of 546 responses (these were excluded from the analyses). Of those, 42 respondents had left the whole of questionnaire B empty, leaving 21 PEI scores (3.8\%) that were not calculable.

The distributions of the PEI answers immediately after the appointment are presented in Table 3. The option "less" was chosen 39 times out of 2898 answers (1.3\%). In their original work to develop the PEI, Howie et al. decided to merge the "less" and "same" options, because only $1 \%$ of respondents chose the option "less" in any of the questions [6]. Thus, we adhered to this conclusion and combined the options "less" and "same". Furthermore, the option "not applicable" was chosen 86 times out of 2898 answers (3.0\%). Altogether 23 answers $(0.8 \%)$ were missing. In general, the acceptability of the PEI in the Finnish context can be considered good. 

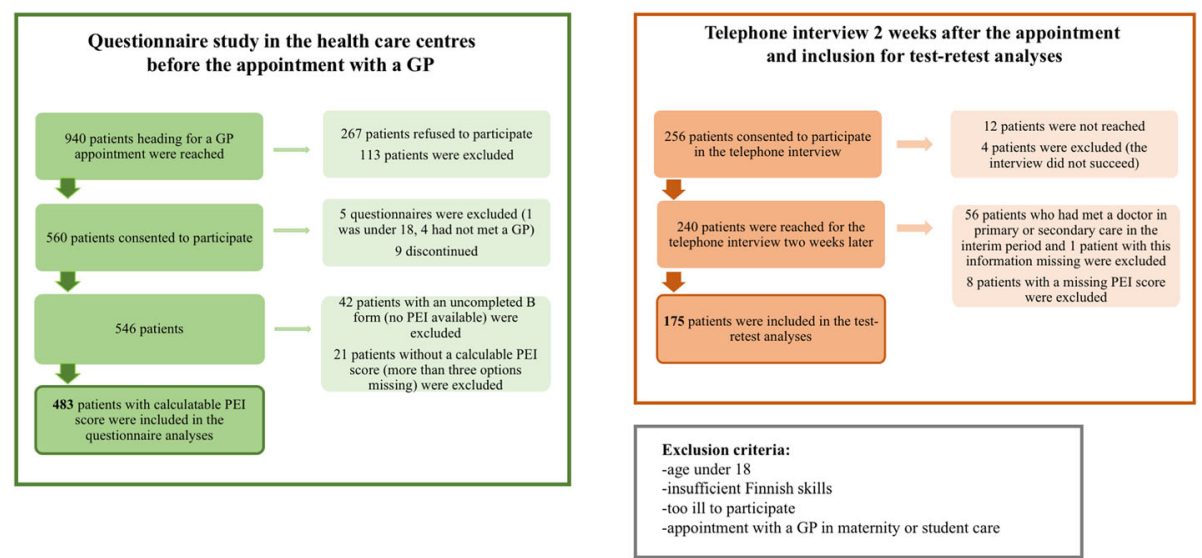

Fig. 4 Data collection process and division for the analyses

\section{Construct validity: structural validity}

The unidimensionality of the scale was evaluated by principal component factor analysis with Varimax rotation. The factor analysis produced one factor with an eigenvalue $>1$, and it explained $73 \%$ of the variance at the baseline and $61 \%$ of the variance after the two-week interval. Each scale item had a similar factor loading (data not shown).

Spearman correlations for each item and the PEI score are presented in Table 4. All correlations were strong (Spearman's rho 0.79-0.84 at the baseline and 0.65-0.76 at the retest) and significant at the 0.01 level.

\section{Construct validity: hypotheses testing}

The correlations between the PEI items or total PEI score and the comparison questions are presented in Table 5. There were weak (Spearman's rho 0.15-0.33) correlations present.

The test hypotheses that patients with a worse state of health have lower PEI scores and that there is no difference between groups when considering age and sex were supported (data not shown). There were no differences in the distributions or means of the PEI score when comparing groups by the number of chronic illnesses or the consultation reason (neither acute vs long-term issue nor one vs more than one issue).

\section{Internal consistency}

Cronbach's alpha for the PEI items was 0.93 (95\% CI $0.91-0.94, p<0.001)$ at the baseline and 0.87 (95\% CI $0.84-0.90, p<0.001)$ at the retest, indicating good internal consistency. It was lower $(0.906-0.914$ at the baseline and 0.84-0.86 at the retest) when any of the six items were deleted, confirming the interrelatedness of the items.

\section{Reliability (reproducibility)}

When analysing the patients who had participated in the telephone interview and not met a doctor in primary or secondary care in the interim period $(n=175)$, the mean PEI score immediately after the appointment was 4.13 (range 0-12, SD 3.95). After the two-week interval, the mean PEI score was 2.78 (range 0-12, SD 3.0). The Wilcoxon signed rank test showed the difference of means to be statistically significant $(\mathrm{Z}=-5.29, \mathrm{p}<0.001)$. Kappa statistics showed only weak agreement $(0.23-0.29)$ on all the questions.

\section{Reliability (measurement error)}

The standard error of measurement for the PEI score was: $\quad S E M=3.83 \sqrt{1-0.93}=3.83 * 0.26=0.996 \approx 1.0$ points, using the Cronbach's alpha coefficient immediately after the appointment. Calculated with the testretest reliability coefficient (Cohen's Kappa mean 0.26), the SEM for the PEI in this study was $2.97 * 0.74=$ $2.198 \approx 2.2$ points.

\section{Discussion}

This is the first study to assess the validity and reliability of the Patient Enablement Instrument (PEI) in the Finnish context. The PEI seems to have good acceptability and content validity, good construct validity (a highly unidimensional structure and relatively successful hypothesis testing), high internal consistency, and moderate to low reliability (a moderate standard error of measurement, but a low test-retest reliability) among Finnish health centre patients.

As was the case in this study, the PEI has been well accepted in different languages and countries $[8,11-14$, 16]. In this study, the mean PEI score was relatively low (3.78), as in previous studies made in Finland [35], Sweden [13], and the UK (particularly those considering 
Table 2 Distributions of the background factors, all participants and by participation in the telephone interview

\begin{tabular}{|c|c|c|c|c|c|c|}
\hline & \multicolumn{2}{|c|}{$\begin{array}{l}\text { All participants, } \\
\boldsymbol{n}=483\end{array}$} & \multicolumn{4}{|c|}{ Comparison by participation in the telephone interview } \\
\hline & \multirow[b]{2}{*}{ Frequency } & \multirow[b]{2}{*}{ Percentage } & \multicolumn{2}{|c|}{$\begin{array}{l}\text { Patients who participated in } \\
\text { the telephone interview and } \\
\text { were included in the test- } \\
\text { retest analyses, } n=175^{\mathrm{a}}\end{array}$} & \multicolumn{2}{|c|}{$\begin{array}{l}\text { Patients who did not } \\
\text { participate in the } \\
\text { telephone interview, } n= \\
254^{* *}\end{array}$} \\
\hline & & & Frequency & Percentage & Frequency & Percentage \\
\hline \multicolumn{7}{|l|}{$\operatorname{Age}^{* * *}$} \\
\hline Range & \multicolumn{2}{|l|}{$18-97$} & \multicolumn{2}{|l|}{$19-88$} & \multicolumn{2}{|l|}{$18-97$} \\
\hline Mean (SD) & \multicolumn{2}{|l|}{$58.5(19.1)$} & \multicolumn{2}{|l|}{$62.2(17.2)$} & \multicolumn{2}{|l|}{$56.2(20.4)$} \\
\hline Data missing/NA & 17 & 3.5 & 7 & 4.0 & 9 & 3.5 \\
\hline \multicolumn{7}{|l|}{ Mean PEI score immediately after the appointment } \\
\hline Mean (SD) & \multicolumn{2}{|l|}{$3.78(3.83)$} & \multicolumn{2}{|l|}{$4.13(3.95)$} & \multicolumn{2}{|l|}{$3.81(3.86)$} \\
\hline \multicolumn{7}{|l|}{ Sex } \\
\hline Female & 313 & 64.8 & 108 & 61.7 & 173 & 68.1 \\
\hline Male & 153 & 32.8 & 60 & 34.3 & 73 & 28.7 \\
\hline Other & 1 & 0.2 & 0 & 0 & 1 & 0.4 \\
\hline Data missing/NA & 16 & 3.3 & 7 & 4.0 & 7 & 2.8 \\
\hline \multicolumn{7}{|l|}{ Language } \\
\hline Finnish & 455 & 94.2 & 164 & 93.7 & 240 & 94.5 \\
\hline Other & 5 & 1.1 & 2 & 1.1 & 2 & 0.8 \\
\hline Data missing/NA & 23 & 4.8 & 9 & 5.1 & 12 & 4.7 \\
\hline \multicolumn{7}{|l|}{ Co-habitation } \\
\hline Single, divorced, widowed & 199 & 41.2 & 72 & 41.1 & 105 & 41.3 \\
\hline Married, registered partnership, or common-law marriage & 267 & 55.3 & 96 & 54.9 & 140 & 55.2 \\
\hline Data missing/NA & 17 & 3.5 & 7 & 4.0 & 9 & 3.5 \\
\hline \multicolumn{7}{|l|}{ Education $* * *$} \\
\hline No qualifications obtained or primary education (lower-level) & 119 & 24.9 & 41 & 23.4 & 65 & 25.6 \\
\hline Upper secondary level of education (middle-level) & 245 & 50.7 & 80 & 45.7 & 141 & 55.5 \\
\hline Post-secondary or higher (higher-level) & 98 & 20.3 & 47 & 26.9 & 37 & 14.6 \\
\hline Data missing/NA & 21 & 4.3 & 7 & 4.0 & 11 & 4.3 \\
\hline \multicolumn{7}{|l|}{ Working status*** } \\
\hline Working & 92 & 19.0 & 21 & 12.0 & 61 & 24.0 \\
\hline Retired & 275 & 56.9 & 112 & 64.0 & 135 & 53.1 \\
\hline Other (unemployed, student, other) & 99 & 20.5 & 34 & 19.4 & 51 & 20.1 \\
\hline Data missing/NA & 17 & 3.5 & 8 & 4.6 & 7 & 2.8 \\
\hline \multicolumn{7}{|l|}{ State of health (self-assessment) } \\
\hline Excellent & 32 & 6.6 & 10 & 5.7 & 21 & 8.3 \\
\hline Good & 165 & 34.2 & 66 & 37.5 & 85 & 33.5 \\
\hline Fair & 171 & 35.4 & 60 & 34.3 & 85 & 33.5 \\
\hline Poor & 18 & 3.7 & 6 & 3.4 & 7 & 2.8 \\
\hline Data missing/NA & 97 & 20.1 & 33 & 18.8 & 56 & 22.0 \\
\hline \multicolumn{7}{|l|}{ Number of chronic illnesses $* * *$} \\
\hline No chronic illness & 78 & 16.1 & 22 & 12.6 & 48 & 18.9 \\
\hline One & 116 & 24.0 & 38 & 21.7 & 69 & 27.2 \\
\hline $2-3$ & 191 & 39.5 & 80 & 45.7 & 87 & 34.3 \\
\hline More than 3 & 61 & 12.6 & 26 & 14.9 & 26 & 11.3 \\
\hline
\end{tabular}


Table 2 Distributions of the background factors, all participants and by participation in the telephone interview (Continued)

\begin{tabular}{|c|c|c|c|c|c|c|}
\hline & \multicolumn{2}{|c|}{$\begin{array}{l}\text { All participants, } \\
\boldsymbol{n}=483\end{array}$} & \multicolumn{4}{|c|}{ Comparison by participation in the telephone interview } \\
\hline & \multirow[b]{2}{*}{ Frequency } & \multirow[b]{2}{*}{ Percentage } & \multicolumn{2}{|c|}{$\begin{array}{l}\text { Patients who participated in } \\
\text { the telephone interview and } \\
\text { were included in the test- } \\
\text { retest analyses, } n=175^{\mathrm{a}}\end{array}$} & \multicolumn{2}{|c|}{$\begin{array}{l}\text { Patients who did not } \\
\text { participate in the } \\
\text { telephone interview, } n= \\
254^{* *}\end{array}$} \\
\hline & & & Frequency & Percentage & Frequency & Percentage \\
\hline Data missing/NA & 37 & 7.7 & 9 & 5.1 & 24 & 9.4 \\
\hline \multicolumn{7}{|c|}{ Number of consultation reasons ${ }^{* * *}$} \\
\hline One & 299 & 61.9 & 98 & 56.0 & 170 & 66.9 \\
\hline More than one & 170 & 35.2 & 71 & 40.6 & 77 & 30.3 \\
\hline Data missing/NA & 14 & 2.9 & 6 & 3.4 & 7 & 2.8 \\
\hline \multicolumn{7}{|l|}{ Consultation reason } \\
\hline Acute & 158 & 32.7 & 52 & 29.7 & 83 & 32.7 \\
\hline Non-acute & 311 & 64.4 & 117 & 66.9 & 164 & 64.6 \\
\hline Data missing/NA & 14 & 2.9 & 6 & 3.4 & 7 & 2.8 \\
\hline \multicolumn{7}{|l|}{ Location $* * *$} \\
\hline Semi-rural & 147 & 30.4 & 58 & 33.1 & 63 & 24.8 \\
\hline Urban & 196 & 40.6 & 78 & 44.6 & 108 & 42.5 \\
\hline Rural & 140 & 29.0 & 39 & 22.3 & 83 & 32.7 \\
\hline
\end{tabular}

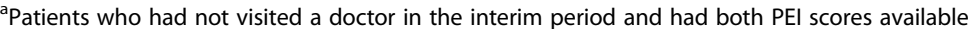
**Patients with no telephone interview and immediate PEI score available **Statistically significant difference between groups in the Chi-square test (bolded), missing values excluded from the analyses Previously published in: Tolvanen, E., Koskela, T.H. \& Kosunen, E. Comparison of the Patient Enablement Instrument (PEI) with two single-item measures among Finnish Health care centre patients. BMC Health Serv Res 19, 376 (2019) doi:https://doi.org/10.1186/s12913-019-4182-2

white, English-speaking patients) [6, 9, 10]. The low mean of the PEI score is often due to the relatively high proportion of patients reporting zero points $[6,10,33]$. In earlier studies, the proportion of patients reporting zero points ranges from $5 \%$ in Japan [16] to $55 \%$ in the Netherlands [33]. In our study, over a quarter $(27.1 \%)$ of patients reported zero points in the PEI.

The construct validity testing confirmed the unidimensional structure of the instrument, as found earlier [6, 14]. The pre-study hypotheses were partly supported. The PEI had only a weak correlation to questions measuring e.g. patient-perceived benefit or satisfaction, suggesting that these are separate concepts. In addition, PEI scores did not differ across gender and age groups, as in one Swedish study [13]. Against the expectations, the PEI distributions and scores seemed to be very similar regardless the number of chronic illnesses or the reason for the consultation. Although this finding is contradictory to previous studies $[17,19]$, it might be interpreted that the PEI could be used in heterogenous patient populations.

In this study, the Cronbach's alpha for the PEI was high (0.93), as in earlier studies $[6,7,9,13,14,16,31$, 32]. For clinical measurements, alpha $>0.90$ is regarded as desirable [40]. On the other hand, high values could reflect overlap or redundancy of the items [41]. Even the use of alpha in general has been questioned [42, 43]. However, the alpha coefficient is only one tool when

Table 3 The distributions of PEI answers, $n=483$

\begin{tabular}{llllll}
\hline $\begin{array}{l}\text { As a result of your visit to the doctor today, do you feel you } \\
\text { are }\end{array}$ & $\begin{array}{l}\text { Much better/ much } \\
\text { more, } \\
\mathrm{n}(\%)\end{array}$ & $\begin{array}{l}\text { Better / } \\
\text { more, } \\
\mathrm{n}(\%)\end{array}$ & $\begin{array}{l}\text { Same or } \\
\text { less, } \\
\mathrm{n}(\%)\end{array}$ & $\begin{array}{l}\text { Not applicable (N/ } \\
\text { A) } \\
\mathrm{n}(\%)\end{array}$ & $\begin{array}{l}\text { Missing, } \\
\mathrm{n}(\%)\end{array}$ \\
\hline Able to understand your illness & $123(25.5)$ & $157(32.5)$ & $191(39.5)$ & $9(1.9)$ & $3(0.6)$ \\
Able to cope with your illness & $98(20.3)$ & $138(28.6)$ & $219(45.3)$ & $20(4.1)$ & $8(1.7)$ \\
Able to keep yourself healthy & $69(14.3)$ & $130(26.9)$ & $260(53.8)$ & $22(4.6)$ & $2(0.4)$ \\
Able to cope with life & $61(12.6)$ & $116(24.0)$ & $289(59.8)$ & $13(2.7)$ & $4(0.8)$ \\
Confident about your health & $83(17.2)$ & $141(29.2)$ & $247(51.1)$ & $10(2.1)$ & $2(0.4)$ \\
Able to help yourself & $68(14.1)$ & $138(28.6)$ & $261(54.0)$ & $12(2.5)$ & $4(0.8)$ \\
\hline
\end{tabular}


Table 4 Spearman correlations between each item and the PEI score at the baseline and retest

\begin{tabular}{lll}
\hline Item & Correlation with total PEI score immediately, $\mathrm{n}=483$ & Correlation with total PEI score 2 weeks after, $\mathrm{n}=175$ \\
\hline Understand illness & 0.82 & 0.76 \\
Cope with illness & 0.84 & 0.73 \\
Keep yourself healthy & 0.82 & 0.65 \\
Cope with life & 0.79 & 0.67 \\
Be confident about your health & 0.83 & 0.76 \\
Help yourself & 0.82 & 0.76
\end{tabular}

All correlations were significant at the 0.01 level

assessing validity and reliability. In practice, it seems that a three-item version of the PEI [10] or a single question [44] are adequate for measuring patient enablement.

To our knowledge, there are no previous calculations of the standard error of measurement (SEM) for the PEI in the literature. The relatively large SEM is mostly caused by the large variation in scores. This could suggest the heterogeneity and diversity of the feelings of enablement. From one point of view, any increase in the patient's feelings of ability and coping should be considered a positive feature in itself. On the other hand, it has been suggested that if the patient is active, wellinformed, and has good self-management prior to the consultation, even a high quality consultation could lead to "no change", meaning 0 points in the PEI measurement [45].

The test-retest reliability of the PEI is low, indicating that feelings of enablement seem to diminish after a rather short period of time. This was seen also in previous studies [13, 15, 34]. Nevertheless, it has been suggested that this is not due to the measurement itself, but to a true "dilution" of experience $[13,15]$. Furthermore, the scores of the comparison questions also diminished statistically significantly over time (data not shown), a phenomenon found with other HR-PROs previously [34]. This confirms the idea that the overall experience is probably at its highest immediately after the consultation. It is therefore important to get the patient to start the planned intervention immediately after the consultation in order to benefit from the increased feelings of ability and coping.

Originally, Howie et al. developed the PEI as an outcome to study whether it is worth using more time in consultations, which are traditionally short in the UK, usually between 5 and $10 \mathrm{~min}[6,46]$. In this study, we did not collect information on consultation times, but in the Finnish primary health care system consultations are usually longer, around 15 to $20 \mathrm{~min}$ [46], and several issues are taken care of during the same consultation. However, in this study, the mean PEI scores and distributions were very similar to those from the UK $[6,9$, 10]. This could indicate that up to a certain point, enablement can be increased by lengthening the consultation time, thus strengthening the patient's feelings of being listened to and taken care of. Nonetheless, it is possible that when the issues at the consultation multiply and become more complex, enablement is no longer dependent on the consultation duration, but on other features instead.

\section{Strengths and limitations}

Our goal was to reach the total sample of patients who visited a health care centre in 1 week, and we reached the majority of patients heading to GP appointments in

Table 5 Spearman correlations between PEI items or total PEI score and the comparison questions, $\mathrm{n}=483$

\begin{tabular}{|c|c|c|c|c|}
\hline $\begin{array}{l}\text { PEl item / } \\
\text { Comparison } \\
\text { question }\end{array}$ & $\begin{array}{l}\text { I would recommend this } \\
\text { doctor to a friend or a relative }\end{array}$ & $\begin{array}{l}\text { I got benefit from my } \\
\text { appointment with this } \\
\text { doctor }\end{array}$ & $\begin{array}{l}\text { I was involved in the decisions } \\
\text { made at the appointment }\end{array}$ & $\begin{array}{l}\text { I got adequate instructions } \\
\text { to carry on with my care }\end{array}$ \\
\hline Understand illness & 0.27 & 0.28 & 0.24 & 0.28 \\
\hline Cope with illness & 0.19 & 0.28 & 0.24 & 0.25 \\
\hline $\begin{array}{l}\text { Keep yourself } \\
\text { healthy }\end{array}$ & 0.15 & 0.18 & 0.15 & 0.22 \\
\hline Cope with life & 0.20 & 0.21 & 0.19 & 0.24 \\
\hline $\begin{array}{l}\text { Keep confident } \\
\text { about your health }\end{array}$ & 0.18 & 0.27 & 0.21 & 0.24 \\
\hline Help yourself & 0.26 & 0.24 & 0.22 & 0.24 \\
\hline $\begin{array}{l}\text { PEI score } \\
\text { immediately }\end{array}$ & 0.32 & 0.33 & 0.28 & 0.33 \\
\hline
\end{tabular}


the data collection period. Furthermore, the response rate was high. We managed to collect a larger dataset than originally planned, and the statistical power calculation demands were met. The study population matches fairly well the average users of Finnish health care centres, with a slight overrepresentation of female and elderly patients [47]. Regrettably, we could not compare the characteristics of participants and non-participants, and a selection bias is therefore possible. The health care centres were not chosen randomly, but they were located both urban and rural areas with different population structures.

Assessments of the cross-cultural validity, criterion validity, and responsiveness of the PEI were not included in the design of this study. Criterion validity could not be assessed because the PEI itself can be considered the "gold standard" of measuring enablement and there are currently no validated questionnaires on patient enablement in Finnish. In addition, with a cross-sectional study design, the elements of responsiveness could not be evaluated.

Formal research on the validity of the comparison questions has not been made in the Finnish context. Nevertheless, the questions have been used in earlier studies [48, 49]. Indeed, there are very few HR-PRO measurements available that have undergone a strict assessment of their validity and reliability in the Finnish context. With this study, we could assess several aspects of the complex concept of validity and reliability, and this can be considered a major strength.

\section{Conclusions}

The PEI seems to have good psychometric properties among Finnish health centre patients. The results are rather similar to previous studies, even though the Finnish primary care setting is different with e.g. longer consultation times. The strongest features of the PEI are its high internal consistency and structural validity. The low reproducibility of the instrument probably reflects the tendency of feelings of enablement to decrease over time. The elements of responsiveness of the PEI need further evaluation, as do its clinical implications.

Overall, the PEI seems to be an applicable tool for measuring patient enablement - which is considered one aspect of quality - in Finnish health care centres when used immediately after the GP appointment. When assessing quality through the patient's experience, the PEI could be used e.g. along with patient satisfaction measurements to gain a broader understanding. The PEI is generic and could therefore be suitable for GP patients with heterogenous consultation health issues. To achieve feelings of ability and coping would be important to all patients and thus patient enablement should be promoted in GP appointments.
Acknowledgements

We want to thank all the GPs and patients who participated in this study.

\section{Authors' contributions}

$E T, E K$, and TK designed the study. ET was a major contributor in drafting the manuscript and performed the statistical analyses. EK, TK, and $\mathrm{MH}$ contributed to the interpretation of the data analysis. They also critically revised the manuscript for important intellectual content. The authors have read and approved the final manuscript.

\section{Funding}

This study was financially supported by the Competitive State Research Financing of the Expert Responsibility Area of Tampere University Hospital, Grant numbers 9 N030 and 9R024. This study was financially supported by Centre for General Practice of Pirkanmaa Hospital District and the City of Tampere.

\section{Availability of data and materials}

The datasets used and analysed during the current study are available from the corresponding author upon reasonable request. After the Patient Enablement in Pirkanmaa study has been completed, the data will be stored to Finnish Social Science Data Archive (FSD).

\section{Ethics approval and consent to participate}

The study design was approved in December 2016 by the Ethics Committee of the Tampere region.

\section{Consent for publication}

Not applicable.

\section{Competing interests}

None.

\section{Author details}

${ }^{1}$ Faculty of Medicine and Health Technology, Tampere University, c/o coordinator Leena Kiuru, Arvo Building B, 33014 Tampere, Finland. ${ }^{2}$ Pirkkala Municipal Health Centre, Pirkkala, Finland. ${ }^{3}$ Research, Development and Innovation Centre, Tampere University Hospital, Tampere, Finland. ${ }^{4}$ Faculty of Social Sciences, Health Sciences, Tampere University, Tampere, Finland. ${ }^{5}$ Centre for General Practice, Pirkanmaa Hospital District, Tampere, Finland.

Received: 13 January 2020 Accepted: 25 August 2020

Published online: 16 September 2020

\section{References}

1. Fitzpatrick, R., Davey, C., Buxton, M. J., \& Jones, D. R. (1998). Evaluating patient-based outcome measures for use in clinical trials. Health Technology Assessment (Rockv), 2, i-74.

2. Valtioneuvosto (Finnish Government) (2018). Maakunta- ja sote-uudistus. Regional government, health and social services reform https://alueuudistus.fi/ en/freedom-of-choice-for-customers.

3. Mokkink, L. B., Terwee, C. B., Patrick, D. L., et al. (2010). The COSMIN study reached international consensus on taxonomy, terminology, and definitions of measurement properties for health-related patient-reported outcomes. Journal of Clinical Epidemiology, 63, 737-745. https://doi.org/10.1016/j. jclinepi.2010.02.006.

4. Mokkink, L. B., Terwee, C. B., Patrick, D. L., et al. (2010). The COSMIN checklist for assessing the methodological quality of studies on measurement properties of health status measurement instruments: An international Delphi study. Quality of Life Research, 19, 539-549. https://doi.org/10.1007/ s11136-010-9606-8.

5. Mokkink, L. B., de Vet, H. C. W., Prinsen, C. A. C., et al. (2018). COSMIN risk of bias checklist for systematic reviews of patient-reported outcome measures. Quality of Life Research, 27, 1171-1179. https://doi.org/10.1007/s11136-0171765-4.

6. Howie, J. G., Heaney, D. J., \& Maxwell, M. (1997). Measuring quality in general practice. Pilot study of a needs, process and outcome measure. Occasional Paper/Royal College of General Practitioners, i-xii, 1-32.

7. Howie, J. G. R., Heaney, D. J., Maxwell, M., \& Walker, J. J. (1998). A comparison of a patient enablement instrument (PEI) against two established satisfaction scales as an outcome measure of primary care 
consultations. Family Practice, 15, 165-171. https://doi.org/10.1093/fampra/ 15.2.165.

8. Mead, N., Bower, P., \& Hann, M. (2002). The impact of general practitioners' patient-centredness on patients' post-consultation satisfaction and enablement. Social Science \& Medicine, 55, 283-299. https://doi.org/10.1016/ S0277-9536(01)00171-X.

9. Howie, J. G. R., Heaney, D. J., Maxwell, M., et al. (1999). Quality at general practice consultations: Cross sectional survey. BMJ, 319, 738-743. https://doi. org/10.1136/bmj.319.7212.738.

10. Mead, N., Bower, P., \& Roland, M. (2008). Factors associated with enablement in general practice: Cross-sectional study using routinelycollected data. The British Journal of General Practice, 58, 346-352. https:// doi.org/10.3399/bjgp08X280218.

11. Ozvacić Adzić, Z., Katić, M., Kern, J., et al. (2008). Patient, physician, and practice characteristics related to patient enablement in general practice in Croatia: Cross-sectional survey study. Croatian Medical Journal, 49, 813-823. https://doi.org/10.3325/cmj.2008.49.813.

12. Pawlikowska, T. R. B., Nowak, P. R., Szumilo-Grzesik, W., \& Walker, J. J. (2002). Primary care reform: A pilot study to test the evaluative potential of the patient enablement instrument in Poland. Family Practice, 19, 197-201. https://doi.org/10.1093/fampra/19.2.197.

13. Rööst, M., Zielinski, A., Petersson, C., \& Strandberg, E. L. (2015). Reliability and applicability of the patient enablement instrument (PEI) in a Swedish general practice setting. BMC Family Practice, 16. https://doi.org/10.1186/ s12875-015-0242-9.

14. Lam, C. L. K., Yuen, N. Y. K., Mercer, S. W., \& Wong, W. (2010). A pilot study on the validity and reliability of the patient enablement instrument (PEI) in a Chinese population. Family Practice. https://doi.org/10.1093/fampra/ cmq021.

15. Hudon, C., Fortin, M., Rossignol, F., et al. (2011). The patient enablement instrument-French version in a family practice setting: A reliability study. BMC Family Practice, 12, 71. https://doi.org/10.1186/1471-2296-12-71.

16. Kurosawa, S., Matsushima, M., Fujinuma, Y., et al. (2012). Two principal components, coping and independence, comprise patient enablement in Japan: Cross sectional study in Tohoku area. The Tohoku Journal of Experimental Medicine, 227, 97-104. https://doi.org/10.1620/tjem.227.97.

17. Pawlikowska, T. R. B., Walker, J. J., Nowak, P. R., \& Szumilo-Grzesik, W. (2010). Patient involvement in assessing consultation quality: A quantitative study of the patient enablement instrument in Poland. Health Expectations, 13, 13-23. https://doi.org/10.1111/j.1369-7625.2009.00554.x.

18. Cohidon, C., Wild, P., \& Senn, N. (2018). Coping better with health problems after a visit to the family physician: Associations with patients and physicians characteristics. BMC Family Practice, 19. https://doi.org/10.1186/ s12875-018-0712-y.

19. Mercer, S. W., Jani, B. D., Maxwell, M., et al. (2012). Patient enablement requires physician empathy: A cross-sectional study of general practice consultations in areas of high and low socioeconomic deprivation in Scotland. BMC Family Practice, 13. https://doi.org/10.1186/1471-2296-13-6.

20. Freeman, G. K., Rai, H., Walker, J. J., et al. (2002). Non-English speakers consulting with the GP in their own language: A cross-sectional survey. The British Journal of General Practice, 52, 36-38.

21. Denley, J., Rao, J. N., \& Stewart, A. (2003). How do patients rate the quality of consultations in primary care? A patient enablement survey from practices within a primary care trust in Sandwell. Quality in Primary Care, 11, 181-187.

22. Bikker, A. P., Mercer, S. W., \& Reilly, D. (2005). A pilot prospective study on the consultation and relational empathy, patient enablement, and health changes over 12 months in patients going to the Glasgow homoeopathic hospital. Journal of Alternative and Complementary Medicine, 11, 591-600. https://doi.org/10.1089/acm.2005.11.591.

23. Mercer, S. W., Fitzpatrick, B., Gourlay, G., et al. (2007). More time for complex consultations in a high-deprivation practice is associated with increased patient enablement. The British Journal of General Practice, 57, 960-966. https://doi.org/10.3399/096016407782604910.

24. Kelly, M., Egbunike, J. N., Kinnersley, P., et al. (2010). Delays in response and triage times reduce patient satisfaction and enablement after using out-ofhours services. Family Practice, 27, 652-663. https://doi.org/10.1093/fampra/ cmq057.

25. Tolvanen, E., Koskela, T. H., Helminen, M., \& Kosunen, E. (2017). Patient enablement after a single appointment with a GP: Analysis of finnish
QUALICOPC data. Journal of Primary Care and Community Health, 8, 213220. https://doi.org/10.1177/2150131917730211.

26. Pawlikowska, T., Zhang, W., Griffiths, F., et al. (2012). Verbal and non-verbal behavior of doctors and patients in primary care consultations - how this relates to patient enablement. Patient Education and Counseling, 86, 70-76. https://doi.org/10.1016/j.pec.2011.04.019.

27. Mercer, S. W., Neumann, M., Wirtz, M., et al. (2008). General practitioner empathy, patient enablement, and patient-reported outcomes in primary care in an area of high socio-economic deprivation in Scotland-a pilot prospective study using structural equation modeling. Patient Education and Counseling, 73, 240-245. https://doi.org/10.1016/j.pec.2008.07.022.

28. Frost, J., Currie, M. J., \& Cruickshank, M. (2015). An integrative review of enablement in primary health care. Los Angeles: SAGE PublicationsSage CA.

29. McKinley, R. K., Fraser, R. C., Baker, R. H., \& Riley, R. D. (2004). The relationship between measures of patient satisfaction and enablement and professional assessments of consultation competence. Medical Teacher, 26, 223-228. https://doi.org/10.1080/01421590410001683186.

30. McKinstry, B., Colthart, l., \& Walker, J. (2006). Can doctors predict patients' satisfaction and enablement? A cross-sectional observational study. Family Practice, 23, 240-245. https://doi.org/10.1093/fampra/cmi111.

31. Hudon, C., St-Cyr Tribble, D., Legare, F., et al. (2010). Assessing enablement in clinical practice: A systematic review of available instruments. Journal of Evaluation Clinical Practice, 16, 1301-1308. https://doi.org/10.1111/j.13652753.2009.01332.x

32. Wensing, M., Wetzels, R., Hermsen, J., \& Baker, R. (2007). Do elderly patients feel more enabled if they had been actively involved in primary care consultations? Patient Education and Counseling, 68, 265-269. https://doi. org/10.1016/j.pec.2007.06.012.

33. Weenink, J. W., Braspenning, J., \& Wensing, M. (2014). Patient reported outcome measures (PROMs) in primary care: An observational pilot study of seven generic instruments. BMC Family Practice, 15. https://doi.org/10.1186/ 1471-2296-15-88.

34. Edwards, A., Elwyn, G., Hood, K., et al. (2004). Patient-based outcome results from a cluster randomized trial of shared decision making skill development and use of risk communication aids in general practice. Family Practice, 21, 347-354. https://doi.org/10.1093/fampra/cmh402.

35. Kuusela, M. (2014). Yleislääkärin vastaanottotapahtuma - näkökulmia laatuun. University of Turku.

36. Streiner, D. L., \& Norman, G. R. (2008). Health measurement scales: A practical guide to their development and use.

37. Lam, T. H., Kleevans, J. W. L., \& Wong, C. M. (1988). Doctor-consultation in Hong Kong: A comparison between findings of a telephone interview with the general household survey. Community Medicine, 10, 175-179.

38. Terveyden ja hyvinvoinnin laitos (2014). Opas toimintakyvyn mittarin arviointiin TOIMIA-verkostossa (1.0) https:/thl.fi/documents/974257/1449823/ Mittariopas_VALMIS_090614+(2).pdf/b53595b9-15b8-4fa3-8765-23cd9221 de8f.

39. Tighe, J., McManus, I. C., Dewhurst, N. G., et al. (2010). The standard error of measurement is a more appropriate measure of quality for postgraduate medical assessments than is reliability: An analysis of MRCP (UK) examinations. BMC Medical Education, 10, 40. https://doi.org/10.1186/14726920-10-40.

40. Bland, J. M., \& Altman, D. G. (1997). Statistics notes: Cronbach's alpha. BMJ, 314, 572. https://doi.org/10.1136/bmj.314.7080.572.

41. Tavakol, M., \& Dennick, R. (2011). Making sense of Cronbach's alpha. International Journal of Medical Education, 2, 53-55.

42. Cho, E., \& Kim, S. (2015). Cronbach's coefficient alpha. Organizational Research Methods, 18, 207-230. https://doi.org/10.1177/1094428114555994.

43. Sijtsma, K. (2009). On the use, the misuse, and the very limited usefulness of cronbach's alpha. Psychometrika, 74, 107-120. https://doi.org/10.1007/ s11336-008-9101-0.

44. Tolvanen, E., Koskela, T. H., \& Kosunen, E. (2019). Comparison of the patient enablement instrument (PEI) with two single-item measures among Finnish health care Centre patients. BMC Health Services Research, 19, 376. https:// doi.org/10.1186/s12913-019-4182-2.

45. Brusse, C. J., \& Yen, L. E. (2013). Preferences, predictions and patient enablement: A preliminary study. BMC Family Practice, 14. https://doi.org/10. 1186/1471-2296-14-116.

46. Irving, G., Neves, A. L., Dambha-Miller, H., et al. (2017). International variations in primary care physician consultation time: A systematic review of 67 countries. BMJ open 7. https://doi.org/10.1136/bmjopen-2017-017902. 
47. Terveyden ja hyvinvoinnin laitos THL (2014). Perusterveydenhuolto 2014. Tilastoraportti - statistical report http://urn.fi/URN:NBN:fi-fe2016051011549.

48. Schäfer, W. L. A., Boerma, W. G. W., Kringos, D. S., et al. (2013). Measures of quality, costs and equity in primary health care instruments developed to analyse and compare primary care in 35 countries. Quality in Primary Care, 21, 67-79.

49. Kangaspunta, V., Koskela, T., Soini, E., \& Ryynänen, O.-P. (2014). Potilaiden arvioon terveyskeskuskäynnin hyödyistä vaikuttavat tekijät. Suom Lääkäril, 69 1654-1659.

\section{Publisher's Note}

Springer Nature remains neutral with regard to jurisdictional claims in published maps and institutional affiliations.

\section{Submit your manuscript to a SpringerOpen ${ }^{\circ}$ journal and benefit from:}

- Convenient online submission

- Rigorous peer review

- Open access: articles freely available online

- High visibility within the field

- Retaining the copyright to your article

Submit your next manuscript at $\boldsymbol{\sim}$ springeropen.com 